\title{
Effect of CYP2D6 Genotypes on the Metabolism of Haloperidol in a Japanese Psychiatric Population
}

\author{
Toshiyuki Someya*,', Kazutaka Shimoda², Yutaro Suzuki', Satoshi Sato', Yoshiaki Kawashima', Genta \\ Hirokane $^{3}$, Sachiyo Morita ${ }^{3}$, Aya Yokono ${ }^{3}$, Saburo Takahashi ${ }^{4}$ \\ 'Department of Psychiatry, Niigata University Graduate School of Medical and Dental Sciences, Niigata, Japan; ${ }^{2}$ Department of Psychiatry, \\ Dokkyo University School of Medicine, Mibucho, Tochigi, Japan; ${ }^{3}$ Department of Psychiatry, Shiga University of Medical Science, Otsu, Shiga, \\ Japan; ${ }^{4}$ Saitama Kounan Hospital, Kounancho, Saitama, Japan
}

\begin{abstract}
We investigated the effect of CYP2D6 genotypes on plasma levels of haloperidol (HAL) and reduced haloperidol (RHAL) in 88 Japanese schizophrenic inpatients being treated with HAL. Some subjects carrying CYP2D6*5 allele (CYP2D6*I/CYP2D6*5, CYP2D6*5/ CYP2D6*10) showed extremely high concentrations of both HAL and RHAL, and the groups with CYP2D6*5 allele seemed to have higher plasma concentrations of HAL $(1.14 \pm 0.69 \mathrm{ng} / \mathrm{ml} / \mathrm{mg})$ and $\mathrm{RHAL}(1.10 \pm 1.05 \mathrm{ng} / \mathrm{ml} / \mathrm{mg})$ than the other groups. Among those without CYP2D6*5 allele, there were no significant differences in plasma concentrations of HAL and RHAL between those without CYP2D6*10 allele $(H A L=0.68 \pm 0.31 \mathrm{ng} / \mathrm{ml} / \mathrm{mg}, \mathrm{RHAL}=0.28 \pm 0.37 \mathrm{ng} / \mathrm{ml} / \mathrm{mg})$, those with one CYP2D6*10 (HAL=0.70 $\pm 0.23 \mathrm{ng} /$ $\mathrm{ml} / \mathrm{mg}, \mathrm{RHAL}=0.31 \pm 0.16 \mathrm{ng} / \mathrm{ml} / \mathrm{mg})$ and those with two CYP2D6*10 alleles $(H A L=0.69 \pm 0.14 \mathrm{ng} / \mathrm{ml} / \mathrm{mg}, \mathrm{RHAL}=0.40 \pm 0.09 \mathrm{ng} /$ $\mathrm{ml} / \mathrm{mg}$ ), although there was a tendency of higher plasma concentration of RHAL in those with two CYP2D6*10 alleles. At a lower daily dosage of HAL ( $<10 \mathrm{mg} /$ day), the subjects with two or one CYP2D6*10 allele(s) showed significantly higher plasma concentrations of $\operatorname{RHAL}(0.43 \pm 0.23 \mathrm{ng} / \mathrm{ml} / \mathrm{mg}, 0.34 \pm 0.16 \mathrm{ng} / \mathrm{ml} / \mathrm{mg})$ than those without CYP2D6*10 allele $(0.18 \pm 0.16 \mathrm{ng} / \mathrm{ml} / \mathrm{mg})$. The results of this study indicate that CYP2D6*10 allele plays significant but modest role in HAL metabolism in Japanese; nevertheless, we should not lump CYP2D6*10 allele with CYP2D6*5 allele because these two mutated alleles seem to have different impacts in the metabolism of HAL. Neuropsychopharmacology (2003) 28, I 50 I - I505, advance online publication, 4 June 2003; doi: I 0.1038/s..npp. I 3002 I 3
\end{abstract}

Keywords: antipsychotics; drug metabolism; haloperidol; reduced haloperidol; CYP2D6*5; CYP2D6*10

\section{INTRODUCTION}

Haloperidol (HAL) is an antipsychotic drug, which is widely used in the treatment of schizophrenia and other psychiatric disorders. The plasma concentration of HAL varies widely among individuals (Someya et al, 1990), which has been thought to have some clinical implications. Several metabolic pathways of HAL, including oxidative $\mathrm{N}$-dealkylation (Gorrod and Fang, 1993), carbonyl reduction yielding reduced haloperidol (RHAL) (Inaba and Kovacs, 1989), and glucuronide conjugation (Oida et al, 1989; Someya et al, 1992) have been intensively studied. It has also been shown that RHAL is reversely oxidized to HAL (Tyndale et al, 1991).

\footnotetext{
*Correspondence: Dr T Someya, Department of Psychiatry, Niigata University Graduate School of Medical and Dental Sciences, 757 Asahimachidori-ichibancho, Niigata 95।-85।0, Japan, Tel: +8I 25227 2209, Fax: +8I 25227 0777, E-mail: someya@med.niigata-u.ac.jp Received 16 August 2002; revised 12 February 2003; accepted 16 April 2003

Online publication: 28 April 2003 at http://www.acnp.org/citations/ Npp042802312/default.pdf
}

In vitro (Inaba et al, 1985; Tyndale et al, 1991) and in vivo (Gram et al, 1989; Llerena et al, 1992a,b) studies have suggested the involvement of CYP2D6 in the metabolism of HAL, and the disposition of HAL is related to the polymorphic debrisoquine oxidation phenotype, which represents the activity of CYP2D6. Llerena et al (1992a, b) investigated the metabolism of HAL and RHAL after single doses of HAL in extensive metabolizers (EMs) and poor metabolizers (PMs) of debrisoquine, finding the clearance of HAL to be significantly lower in PMs than in EMs. Also, plasma levels of RHAL were significantly higher in PMs than in EMs. These results also suggested the involvement of CYP2D6 in the metabolism of HAL.

Recently, the molecular genetic basis for interethnic differences in the distribution of CYP2D6 activity has been revealed. The major defect CYP2D6 alleles causing absent enzyme activity in white patients are CYP2D $6^{*} 3\left({ }^{*}\right)$, $C Y P 2 D 6^{\star} 4\left({ }^{*}\right)$, and $C Y P 2 D 6^{\star 5}\left({ }^{*}\right)$, with frequencies of $2.3 \%, 21.5 \%$, and $4 \%$, respectively (Bertilsson and Dahl, 1996). However, in Asian patients, the allele frequencies of ${ }^{\star} 3,{ }^{\star} 4$, and ${ }^{\star} 5$ have been reported to be $0,0.4$, and $5.7 \%$, respectively (Johansson et al, 1994). On the other hand, $C Y P 2 D 6^{\star} 10\left({ }^{*} 10\right)$, which causes decreased enzyme activity, 
is found with a higher frequency in Asian populations (51\%) (Johansson et al, 1994) compared to that in white populations (2.8\%) (Bertilsson and Dahl, 1996). The high frequency of ${ }^{\star} 10$ allele in Asian populations might be an important factor in the HAL metabolism of Asian patients.

There have been several studies on the impact of $* 5$ or ${ }^{\star} 10$ alleles on plasma concentrations of HAL and RHAL in Japanese patients with schizophrenia. Suzuki et al (1997) investigated the effects of the number of $* 5$ or $* 10$ in Japanese schizophrenic patients in steady-state plasma concentrations of HAL and RHAL. The mean plasma concentrations of HAL were significantly $(p<0.05)$ higher in patients with one mutated allele than in those with no mutated allele. The mean plasma concentrations of RHAL were significantly $(p<0.05)$ higher in patients with one or two mutated allele(s) than in those with no mutated allele.

In our preliminary study (Someya et al, 1999), there was a significant tendency for the plasma concentrations of HAL to be higher in subjects who had the ${ }^{\star} 5$ allele than in those with the CYP2D $6^{\star} 1\left({ }^{*} 1\right) /{ }^{\star} 1$ genotype, and plasma concentrations of RHAL were significantly higher in those subjects with the $\star 5$ allele than in those without $* 5$, including those with the ${ }^{\star} 10 /{ }^{*} 10$ genotype. Although our results and those of Suzuki et al (1997) suggest that CYP2D6 contributed to the HAL metabolism at least in part, Suzuki et al (1997) examined only the impact of the number of CYP2D6 mutated alleles. Unlike their study, we specifically examined patients with $\star_{5}$ allele and suggest that $\star_{5}$ and ${ }^{*} 10$ alleles should not be treated in a lump as mutated allele of same impact on the individual metabolic capacity for HAL.

On the other hand, previous results were not consistent regarding the impact of ${ }^{\star} 10$ allele on plasma concentrations of HAL and RHAL; some studies have suggested that ${ }^{*} 10$ allele had a significant effect (Mihara et al, 1999), while others reported no significant effect of ${ }^{\star} 10$ allele (Shimoda et al, 2000).

The present study investigated the effect of CYP2D6 mutated alleles on plasma levels of HAL and RHAL in 88 Japanese schizophrenic inpatients being treated with HAL.

\section{MATERIALS AND METHODS}

\section{Patients}

This study was approved by the ethics committee and the gene ethics committee of Niigata University School of Medicine. Informed consent was obtained from each subject before entry to the present study. Subjects were 88 (59 male, 29 female) Japanese schizophrenic inpatients diagnosed by DSM-IV. All were hospitalized at the Saitama Kounan Hospital and aged 27-73 years (mean $\pm S D=53.1 \pm 9.4$ ). None of the subjects in the present study had obvious general medical conditions. The body weights of patients ranged from 33.0 to $84.0 \mathrm{~kg}(58.2 \pm 10.9)$. They were treated exclusively with HAL per os. Additional drugs were not allowed other than biperiden, trihexyphenidyl, and laxatives, which are not known to affect plasma HAL concentrations. Demographic data, medical histories, and laboratory data, including hematology, serology, electrolytes, and urine analysis, were collected from each patient. Patients who took other antipsychotic drugs such as phenothiazine were excluded from the study. Daily dosages of HAL were titrated at $2.0-42.0 \mathrm{mg}(12.5 \pm 8.7)$ according to each patient's clinical symptomatology. The nursing staff confirmed the compliance of patients at each medication.

\section{Blood Sampling}

Patients were maintained on the same daily dosage of HAL for at least 2 months, which means that all of the patients in the present study had steady-state HAL concentrations. A measure of $7 \mathrm{ml}$ of venous blood was collected at $06.00 \mathrm{am}$, that is, $12 \mathrm{~h}$ after the evening dose, into a Venoject ${ }^{\circledR}$ tube with EDTA-Na (Terumo Japan, Tokyo, Japan). Within $2 \mathrm{~h}$ after collection, blood samples were centrifuged at $3000 \mathrm{~g}$ and aliquots of plasma were drawn out and stored at $-80^{\circ} \mathrm{C}$ to determine plasma levels of HAL and RHAL. After the plasma was drawn, the remaining cell fractions were frozen and also stored at $-80^{\circ} \mathrm{C}$ to analyze the CYP2D6 genotype.

\section{Measuring Plasma Levels of HAL and RHAL}

The plasma concentrations of HAL and RHAL were measured using column-switching high-performance liquid chromatography with ultraviolet detection according to the method of Hikida et al (1989), which was originally developed to determine plasma levels of bromperidol, which is an analogue of HAL.

The plasma, to which trifluperidol had been added as an internal standard, was extracted with hexane-chloroform, and the extract was subjected to automated columnswitching HPLC using a hydrophilic meta-acrylate polymer column for sample clean-up and a reversed-phase column for separation. The lowest limit of detection was $0.3 \mathrm{ng} / \mathrm{ml}$, and the inter-assay coefficient of variation was less than $5 \%$ at concentrations of $1 \mathrm{ng} / \mathrm{ml}$ for both HAL and RHAL.

\section{Genotyping CYP2D6}

To determine the CYP2D6 genotype, DNA was isolated from peripheral leucocytes using a QIAamp Blood Kit (QIAGEN Inc., CA, USA). The ${ }^{\star} 1$ and ${ }^{\star} 10$ alleles were identified as the $\mathrm{C} 188 \mathrm{~T}$ mutation using a two-step polymerase chain reaction (PCR) analysis as described by Johansson et al (1994). A long-PCR analysis was used to detect the ${ }^{\star} 5$ allele, as described by Steen et al (1995). *3 and $* 4$ were screened by the method described by Heim and Meyer (1990).

\section{Statistical Analysis}

The statistical analyses were performed using GraphPad Prism Ver. 3.0 (GraphPad Software, Inc., San Diego, CA, USA). The between-group differences were compared using one-way analysis of variance (ANOVA), and the Bonferroni test was used for post hoc analysis. The level of significance was set at less than 0.05 .

\section{RESULTS}

Inter-Individual Variations of Plasma Concentrations of HAL and RHAL

There were significant correlations both between plasma concentration of HAL and dosages of $\mathrm{HAL}(\mathrm{HAL}=0$. 
$675 \times$ Dosage $+0.788, \quad r=0.751, p<0.0001)$ and between plasma concentrations of RHAL and dosages of $\mathrm{HAL}$ (RHAL $=0.412 \times$ Dosage $-0.145, \quad r=0.523, \quad p<0.0001)$. For the following comparison, the plasma concentrations of HAL and RHAL were corrected for daily dosages. The ranges of plasma concentrations of $\mathrm{HAL}$ and RHAL corrected for daily dosages were $0.21-3.18 \mathrm{ng} / \mathrm{ml} /$ $\mathrm{mg} \quad($ mean $\pm \mathrm{SD}=0.76 \pm 0.42)$ and $0.00-3.00 \mathrm{ng} / \mathrm{ml} / \mathrm{mg}$ $(0.38 \pm 0.43)$, respectively. There were approximately 15 fold interindividual variations in the plasma concentrations of HAL.

\section{Relation between CYP2D6 Genotypes and Plasma Concentrations of HAL and RHAL}

Eight CYP2D6 genotypes were identified in the subjects studied: ${ }^{\star} 1{ }^{\star} 1 \quad(n=17),{ }^{\star} 1 / C Y P 2 D 6{ }^{\star} 2\left({ }^{\star} 2\right)(n=12),{ }^{\star} 1{ }^{\star} 5$ $(n=4),{ }^{\star} 1 /^{\star} 10 \quad(n=23),{ }^{\star} 2{ }^{\star} 2 \quad(n=2),{ }^{\star} 2{ }^{\star} 10 \quad(n=14)$, ${ }^{\star} 5{ }^{\star} 10(n=3)$, and ${ }^{\star} 10{ }^{\star} 10(n=13)$. ${ }^{*} 3$ or ${ }^{\star} 4$ alleles were not found. The allele frequencies of ${ }^{\star} 1,{ }^{\star} 2,{ }^{\star} 5$, and ${ }^{\star} 10$ alleles were $41.5,17.0,4.0$, and $37.5 \%$, respectively.

It is known that the debrisoquine metabolic ratio of subjects carrying one copy of the $* 2$ gene did not significantly differ from that of subjects with the wild-type gene (Dahl et al, 1995; Johansson et al, 1993). On the contrary, multiple copies of ${ }^{*} 2$ gene result in increased activity of CYP2D6 and clearance of nortriptyline. The apparent oral clearances of nortriptyline were increased in the subjects with two or three functional CYP2D6 genes (Dalén et al, 1998). However, those with ${ }^{*} 2$ allele did not result in increased or decreased activity of CYP2D6 at least in our data. So we categorized ${ }^{*} 2$ allele as the normal function allele in the present study, although we have not identified the multiplication of ${ }^{*} 2$.

Figure 1 shows the relation between CYP2D6 genotypes and plasma concentrations of HAL and RHAL corrected for daily dosage. As shown in Figure 1, some subjects with the genotype carrying ${ }^{*} 5$ allele $\left({ }^{*} 1 /{ }^{*} 5,{ }^{*} 5 /{ }^{*} 10\right)$ showed extremely high concentrations of both HAL and RHAL, and the groups of subjects with $\star 5$ allele seemed to have higher plasma concentrations of HAL $(1.14 \pm 0.69 \mathrm{ng} / \mathrm{ml} / \mathrm{mg})$ and RHAL $(1.10 \pm 1.05 \mathrm{ng} / \mathrm{ml} / \mathrm{mg})$ than the other groups. However, because of the small number of subjects with $* 5$ allele $\left({ }^{*} 1{ }^{\star} 5(n=4),{ }^{*} 5 /{ }^{\star} 10(n=3)\right)$, only the data from subjects without $\star 5$ allele were subjected to statistical analysis. The 81 subjects without $* 5$ allele were categorized into three groups according to the number of $\star 10$ allele as shown in Figure 1. There were no significant differences in plasma concentrations of HAL and RHAL between those without ${ }^{*} 10$ allele $(\mathrm{HAL}=0.68 \pm 0.31 \mathrm{ng} / \mathrm{ml} / \mathrm{mg}, \mathrm{RHAL}=$ $0.28 \pm 0.37 \mathrm{ng} / \mathrm{ml} / \mathrm{mg})$, those with one ${ }^{\star} 10(\mathrm{HAL}=0.70 \pm$ $0.23 \mathrm{ng} / \mathrm{ml} / \mathrm{mg}, \mathrm{RHAL}=0.31 \pm 0.16 \mathrm{ng} / \mathrm{ml} / \mathrm{mg}$ ), and those with two ${ }^{*} 10$ alleles $(\mathrm{HAL}=0.69 \pm 0.14 \mathrm{ng} / \mathrm{ml} / \mathrm{mg}, \mathrm{RHAL}=$ $0.40 \pm 0.09 \mathrm{ng} / \mathrm{ml} / \mathrm{mg}$ ), although there was a tendency of higher plasma concentration of RHAL in those with two ${ }^{*} 10$ alleles (one-way ANOVA: $\mathrm{F}=0.635, \mathrm{df}=2,80, \mathrm{NS} ; \mathrm{F}=0.081$, $\mathrm{df}=2,80, \mathrm{NS})$.

Since different contributions of CYP2D6 have been reported to the metabolism of $\mathrm{HAL}$ between low daily dosage and high daily dosage of HAL (Roh et al, 2001), the subjects in the present study were divided into two groups according to the median daily dosage of HAL $(<10 \mathrm{mg} /$ day
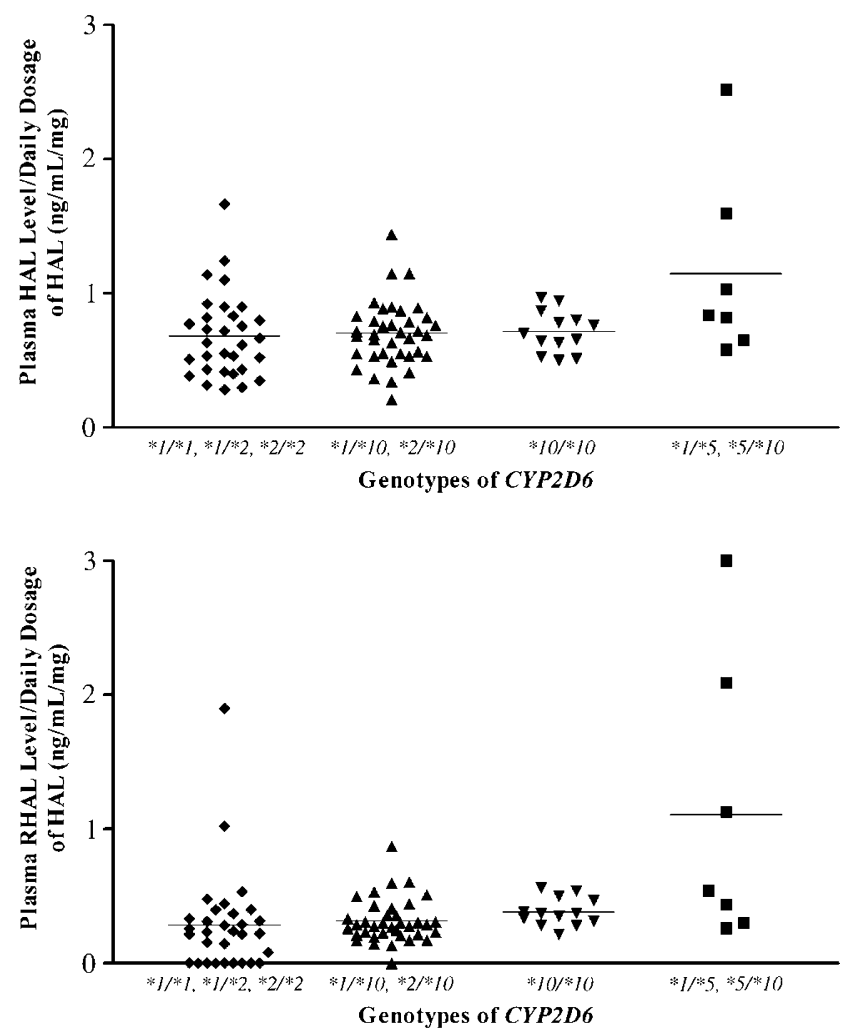

Figure I Relations between CYP2D6 genotypes and steady-state plasma concentrations of HAL and RHAL corrected for daily dose of HAL.

$(n=45)$ or $\geqslant 10 \mathrm{mg} /$ day $(n=43))$, and the impact of CYP2D6 genotypes on the HAL and RHAL plasma levels were investigated. Roh et al (2001) used $20 \mathrm{mg} / \mathrm{day}$ as the cutoff point; however, $20 \mathrm{mg} /$ day is apparently a high daily dosage of HAL in a recent clinical situation. So we set the median daily dosage of $9 \mathrm{mg} /$ day as the cutoff point.

Figure 2 shows the relation between CYP2D6 genotypes and plasma concentrations of HAL and RHAL when the daily dosage of HAL is less than $10 \mathrm{mg} /$ day. For the same reason as described above, only data from the subjects without $\star 5$ alleles $(n=39)$ were subjected to statistical analysis. The 39 subjects without $\star 5$ alleles were categorized into three groups according to the number of $* 10$ allele. There were no significant difference in plasma levels of HAL corrected for daily dosage $(<10 \mathrm{mg} /$ day) among the three groups (ANOVA; $\mathrm{F}=0.621, \mathrm{df}=2,38, \mathrm{NS}$ ), while significant differences were observed in plasma levels of RHAL corrected for daily dosage between genotypes (ANOVA; $\mathrm{F}=5.954, \mathrm{df}=2,38, p<0.005)$. Bonferroni post hoc test revealed that subjects with two or one ${ }^{*} 10$ allele(s) had significantly higher plasma concentrations of RHAL $(0.43 \pm 0.23,0.34 \pm 0.16 \mathrm{ng} / \mathrm{ml} / \mathrm{mg})$ than those without ${ }^{*} 10$ allele $(0.18 \pm 0.16 \mathrm{ng} / \mathrm{ml} / \mathrm{mg})$. The groups of subjects with *5 allele seemed to have higher plasma concentrations of $\operatorname{HAL}(1.16 \pm 0.75 \mathrm{ng} / \mathrm{ml} / \mathrm{mg})$ and RHAL $(1.10 \pm 1.15 \mathrm{ng} / \mathrm{ml} /$ $\mathrm{mg}$ ) than the other three groups.

Figure 3 shows the relation between CYP2D6 genotypes and plasma concentrations of HAL and RHAL when the daily dosage of HAL is more than $10 \mathrm{mg} /$ day. No significant differences were observed in plasma levels of HAL or RHAL among three groups (ANOVA; $\mathrm{F}=0.267$ and 0.983, $\mathrm{df}=2,41$, NS, respectively). 

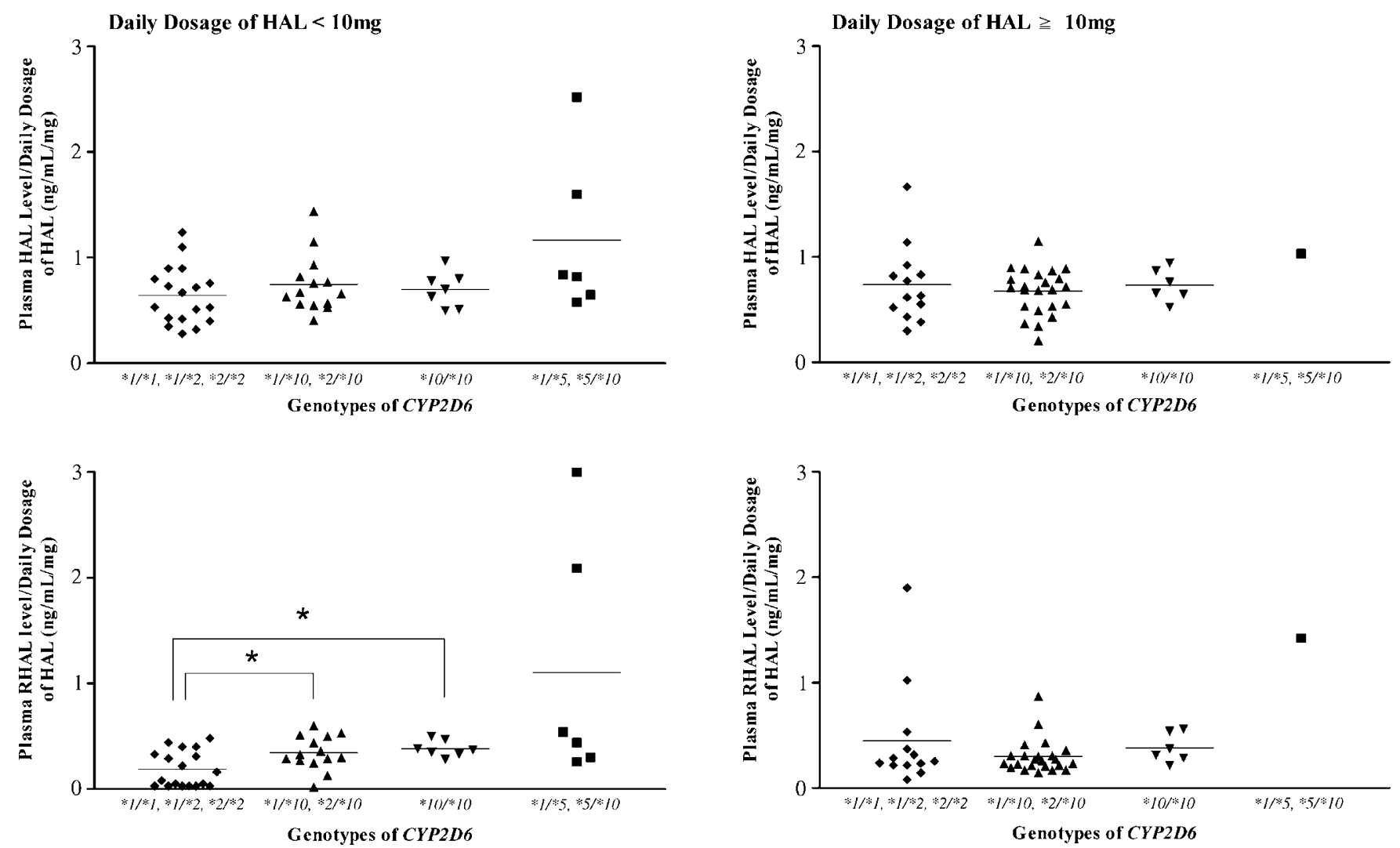

Figure 2 Relations between CYP2D6 genotypes and steady-state plasma concentrations of HAL and RHAL corrected for daily dose of HAL with a lower daily dosage of HAL ( $<10 \mathrm{mg} /$ day $)$.

Figure 3 Relations between CYP2D6 genotypes and steady-state plasma concentrations of $\mathrm{HAL}$ and $\mathrm{RHL}$ corrected for daily dose of $\mathrm{HAL}$ with a higher daily dosage of HAL ( $\geqslant 10 \mathrm{mg} /$ day).

\section{DISCUSSION}

Suzuki et al (1997) investigated the effect of CYP2D6 mutated allele numbers on the plasma concentrations of HAL and RHAL. They reported that the group with one mutated allele had a higher plasma concentration of HAL than the subjects with no mutated allele $(27.3 \pm 11.8 \mathrm{vs}$ $18.4 \pm 8.5 \mathrm{nM}$ ), and the subjects with one or two mutated allele(s) had higher plasma concentrations of RHAL than the group without mutated alleles (Suzuki et al, 1997), which suggests that CYP2D6 genotype is one of the major determinants of the metabolism of HAL.

In our previous study, we studied the effects of $* 5$ and ${ }^{\star} 10$ alleles on the steady-state plasma concentrations of HAL and RHAL in 32 schizophrenic subjects, and reported that the group with the $* 5$ allele had higher plasma concentrations of HAL and RHAL than the subjects with ${ }^{\star} 1 /{ }^{\star} 1$, ${ }^{\star} 1 /{ }^{*} 10$, or ${ }^{\star} 10{ }^{\star} 10$ genotypes (Someya et al, 1999). Also in the present study, significant differences were observed in plasma levels of HAL and RHAL between genotypes, in the subjects treated with $\mathrm{HAL}<10 \mathrm{mg} /$ day. The subjects with $\star_{5}$ allele $(1.16 \pm 0.75 \mathrm{ng} / \mathrm{ml} / \mathrm{mg})$ had significantly higher plasma concentrations of HAL than those without ${ }^{*} 10$ or $\star_{5}$ allele $(0.64 \pm 0.27 \mathrm{ng} / \mathrm{ml} / \mathrm{mg})$, which is compatible with the result in our previous study. These results suggest that the ${ }^{*} 5$ allele is a significant determinant of plasma levels of HAL, especially in Japanese subjects treated with HA$\mathrm{L}<10 \mathrm{mg} /$ day. However, further investigation is still needed for clarifying the effect of genotype carrying $\star^{5}$ allele(s) because of the sample size limitation.

Regarding the impact of ${ }^{\star} 10$ allele, no significant differences were observed in the plasma levels of HAL or RHAL among the subjects with no, one, and two ${ }^{\star} 10$ allele(s) (see Figure 1). On the other hand, significant differences were observed in the plasma levels of RHAL between the subjects without ${ }^{\star} 10$ allele and those with ${ }^{\star} 10$ allele(s) (see Figure 2). Previous results were not consistent on the impact of $* 10$ allele on the plasma concentrations of HAL and RHAL. Mihara et al (1999) studied the effects of ${ }^{*} 10$ allele on the steady-state plasma concentrations of HAL and RHAL. The subjects were 67 Japanese schizophrenic inpatients who had only ${ }^{*} 1$ or ${ }^{\star} 10$ alleles. The mean plasma concentration of HAL was significantly $(p<0.05)$ higher in patients with one ${ }^{\star} 10$ allele than in those without ${ }^{\star} 10$ alleles. The mean plasma concentrations of RHAL were significantly $(p<0.05)$ higher in patients with one and two ${ }^{\star} 10$ allele(s) than in those without ${ }^{\star} 10$ allele. On the other hand, Shimoda et al (2000) studied the impact of ${ }^{\star} 10$ alleles on the plasma concentrations of HAL in 66 Japanese inpatients with schizophrenia without $\star_{3},{ }^{*}$, or $\star_{5}$ alleles. No significant difference was observed in plasma concentrations of HAL among subjects with no, one, and two ${ }^{*} 10$ allele(s) in the subgroup of $<0.3 \mathrm{mg} / \mathrm{kg}$ of $\mathrm{HAL}$ and in another subgroup of $\geqslant 0.3 \mathrm{mg} / \mathrm{kg}$ of HAL. In addition to these discrepancies, it is somewhat strange that Mihara et al (1999) did not find any significant difference in plasma concentrations of HAL between those with two $* 10$ alleles and those without $* 10$ alleles, although they found significant difference between those with one ${ }^{\star} 10$ allele 
and those without ${ }^{*} 10$ alleles. It is just the same with the result of Suzuki et al (1997) that they did not identify the significant difference between the group with two mutated alleles and the subjects with no mutated allele, although they reported that the group with one mutated allele had a higher plasma concentration of HAL than the subjects with no mutated allele. All these discrepancies might be explained by the weak impact of ${ }^{\star} 10$ alleles on the enzymatic activity of CYP2D6, that is, ${ }^{*} 10$ allele results in only reduced activity of CYP2D 6 while ${ }^{\star}$ allele is a defective allele. Additional explanation is that the involvement of CYP2D6 in the metabolism of HAL may not be as strong as in those of RHAL.

In conclusion, ${ }^{\star} 10$ allele plays a significant but modest role in HAL metabolism in Japanese psychiatric population; nevertheless, ${ }^{\star} 5$ allele possibly have a more important role in determining plasma HAL concentration. So we should not lump ${ }^{*} 10$ allele with ${ }^{*}$ allele because these two mutated alleles seem to have different impacts in the metabolism of HAL.

\section{ACKNOWLEDGEMENTS}

This research was supported by Grant in Aid for Scientific Research (KAKENHI) from the Japan Society for the Promotion of Research (JSPS) \#13670991 and \#13671000).

\section{REFERENCES}

Bertilsson L, Dahl ML (1996). Polymorphic drug oxidation. Relevance to the treatment of psychiatric disorders. CNS Drugs 5: 200-223.

Dahl ML, Johansson I, Bertilsson L, Ingelman Sundberg M, Sjöqvist F (1995). Ultrarapid hydroxylation of debrisoquine in a Swedish population. Analysis of the molecular genetic basis. $J$ Pharmacol Exp Ther 274: 516-520.

Dalén P, Dahl ML, Ruiz ML, Nordin J, Bertilsson L (1998). 10Hydroxylation of nortriptyline in white persons with $0,1,2,3$, and 13 functional CYP2D6 genes. Clin Pharmacol Ther 63: 444452.

Gorrod JW, Fang J (1993). On the metabolism of haloperidol. Xenobiotica 23: 495-508.

Gram LF, Debruyne D, Caillard V, Boulenger JP, Lacote J, Moulin $M$ et al (1989). Substantial rise in sparteine metabolic ratio during haloperidol treatment. Br J Clin Pharmacol 27: 272-275.

Heim M, Meyer UA (1990). Genotyping of poor metabolisers of debrisoquine by allele-specific PCR amplification. Lancet 336: 529-532.

Hikida K, Inoue Y, Miyazaki T, Kojima N, Ohkura Y (1989). Determination of bromperidol in serum by automated columnswitching high-performance liquid chromatography. J Chromatogr 495: 227-234.

Inaba $\mathrm{T}$, Jurima $\mathrm{M}$, Mahon WA, Kalow $\mathrm{W}$ (1985). In vitro inhibition studies of two isozymes of human liver cytochrome P450: mephenytoin p-hydroxylase and sparteine monooxygenase. Drug Metab Dispos 13: 443-448.
Inaba T, Kovacs J (1989). Haloperidol reductase in human and guinea pig livers. Drug Metab Dispos 17: 330-333.

Johansson I, Lundqvist E, Bertilsson L, Dahl ML, Sjöqvist F, Ingelman Sundberg M (1993). Inherited amplification of an active gene in the cytochrome P450 CYP2D locus as a cause of ultrarapid metabolism of debrisoquine. Proc Natl Acad Sci USA 90: $11825-11829$.

Johansson I, Oscarson M, Yue Q, Bertilsson L, Sjöqvist F, Ingelman-Sundberg M (1994). Genetic analysis of the Chinese cytochrome P4502D6 locus: characterization of variant CYP2D6 genes present in subjects with diminished capacity for deberisoquine hydroxylation. Mol Pharmacol 46: 452-459.

Llerena A, Alm C, Dahl ML, Ekqvist B, Bertilsson L (1992a). Haloperidol disposition is dependent on debrisoquine hydroxylation phenotype. Ther Drug Monit 14: 92-97.

Llerena A, Dahl ML, Ekqvist B, Bertilsson L (1992b). Haloperidol disposition is dependent on the debrisoquine hydroxylation phenotype: increased plasma levels of the reduced metabolite in poor metabolizers. Ther Drug Monit 14: 261-264.

Mihara K, Suzuki A, Kondo T, Yasui N, Furukori H, Nagashima U et al (1999). Effects of the CYP2D6*10 allele on the steady-state plasma concentrations of haloperidol and reduced haloperidol in Japanese patients with schizophrenia. Clin Pharmacol Ther 65: 291-294.

Oida T, Terauchi Y, Yoshida K, Kagemoto A, Sekine Y (1989). Use of antisera in the isolation of human specific conjugate of haloperidol. Xenobiotica 19: 781-793.

Roh HK, Chung JY, Oh DY, Park CS, Svensson JO, Dahl ML et al (2001). Plasma concentrations of haloperidol are related to CYP2D6 genotype at low, but not high doses of haloperidol in Korean schizophrenic patients. Br J Clin Pharmacol 52: 265-271.

Shimoda K, Morita S, Yokono A, Someya T, Hirokane G, Sunahara $\mathrm{N}$ et al (2000). CYP2D6*10 alleles are not the determinant of the plasma haloperidol concentrations in oriental patients. Ther Drug Monit 22: 392-396.

Someya T, Shibasaki M, Noguchi T, Takahashi S, Inaba T (1992). Haloperidol metabolism in psychiatric patients: importance of glucuronidation and carbonyl reduction. J Clin Psychopharmacol 12: $169-174$

Someya T, Suzuki Y, Shimoda K, Hirokane G, Morita S, Yokono A et al (1999). The effect of cytochrome P450 2D6 genotypes on haloperidol metabolism: a preliminary study in a psychiatric population. Psychiatry Clin Neurosci 53: 593-597.

Someya T, Takahashi S, Shibasaki M, Inaba T, Cheung SW, Tang SW (1990). Reduced haloperidol/haloperidol ratios in plasma: polymorphism in Japanese psychiatric patients. Psychiatry Res 31: 111-120.

Steen VM, Andreassen OA, Daly AK, Tefre T, Borresen A-L, Idle JR et al (1995). Detection of the poor metabolizer-associated CYP2D6(D) gene deletion allele by long-PCR technology. Pharmacogenetics 5: 215-223.

Suzuki A, Otani K, Mihara K, Yasui N, Kaneko S, Inoue Y et al (1997). Effects of the CYP2D6 genotype on the steady-state plasma concentrations of haloperidol and reduced haloperidol in Japanese schizophrenic patients. Pharmacogenetics 7: 415-418.

Tyndale RF, Kalow W, Inaba T (1991). Oxidation of reduced haloperidol to haloperidol: involvement of human P450IID6 (sparteine/debrisoquine monooxygenase). $\mathrm{Br} J$ Clin Pharmacol 31: $655-660$. 